\title{
De Prinkipo a Pulacayo: consideraciones sobre la historia del trotskismo boliviano
}

\section{Steven Sándor John}

City University of New York, Estados Unidos

s_an@msn.com

Title: From Prinkipo to Pulacayo: Some Questions of Bolivian Trotskyism's History

Resumen: En la historia del movimiento trotskista mundial, Bolivia ha ocupado un lugar especial y en cierto grado excepcional. ¿En qué ha consistido la influencia histórica del trotskismo boliviano? ¿Cómo se explica? ¿Cuál fue su politica durante la Revolución Boliviana de 1952 y cuáles fueron los resultados de dicha orientación? En el artículo se plantean algunas consideraciones sobre estos temas.

Palabras clave: Bolivia - trotskismo - Revolución Nacional - mineros

Abstract: Bolivia has occupied a unique place in the history of the world Trotskyist movement. What has Bolivian Trotskyism's historical influence consisted of? How can it be explained? What was the movement's policy during the Bolivian Revolution of 1952 and what were its results? The article presents some considerations on these issues.

Key words: Bolivia - trotskyism - National Revolution - miners

Recepción: 16 de marzo de 2020. Aceptación: 20 de junio de 2020 
En noviembre de 2019, las noticias de Bolivia llamaron la atención del mundo cuando, entre motines policiales y manifestaciones callejeras, fue derrocado Evo Morales y tomó el poder un gobierno de facto, marcado por el protagonismo de políticos ultraderechistas y anti-indigenas, con el respaldo entusiasta del presidente norteamericano Donald Trump y su secretario de Estado Mike Pompeo. Aunque el análisis de estos dramáticos sucesos no cabría en los parámetros de este artículo, resalta nuevamente que en cada uno de los bruscos virajes tan caracteristicos de la historia boliviana, irrumpen cuestiones fundamentales de revolución y contrarrevolución.

Fue a partir de tales cuestiones que surgió hace 85 años el trotskismo boliviano, que por sus caracteristicas particulares -y por el papel que ha jugado en la vida del país- debe abordarse como una variante sui generis del trotskismo latinoamericano y mundial. El trotskismo adquirió un nivel de influencia comparable sólo en Ceilán (que en 1972 cambió su nombre a Sri Lanka) y -hasta 1945, cuando el movimiento fue aniquilado- en la parte de Indochina que hoy es Vietnam.

Al esbozar algunas consideraciones sobre el trotskismo boliviano y su influencia histórica, quiero enfocar tres temas específicos. Hay que subrayar que aquí me limito a la tentativa de sintetizar sólo algunos aspectos de un tema extraordinariamente amplio.

1) Si el trotskismo ha sido excepcionalmente influyente en Bolivia, ¿cuáles serían algunas manifestaciones, características y ejemplos importantes de esta influencia?

2) Si esta doctrina aparentemente exótica, nacida al otro lado del planeta y materializada en una corriente internacional aislada, perseguida y sin recursos, echó raíces en uno de los países más pobres, aislados -y desde la óptica de muchos, también "exóticos"- del hemisferio, entonces ¿Cómo se explica?

3) Junto con la Revolución Mexicana (1910-1917) y la Cubana (1959), la Revolución Boliviana de 1952, conocida dentro del país como la Revolución Nacional, constituye un hito en la historia latinoamericana por haber sido una de las más extensas y profundas del siglo XX. ¿Cómo se orientó políticamente el movimiento trotskista boliviano y -a grandes rasgos- cuáles fueron los resultados de esa orientación?

\section{¿"Una de las curiosidades de Bolivia"?}

En 1960, la revista norteamericana Life, influyente popularizadora de las posiciones de Washington en la Guerra Fría, envió un reportero a Bolivia. En ese momento, la Unión Soviética ofrecía construir una fundidora para el país, que no tenía forma de refinar el estaño de cuya exportación dependía. Cuando los miembros de una delegación soviética 
llegaron al legendario campamento minero de Siglo XX, se asombraron al ver que cientos de mineros -que salieron a dar una acogida calurosa a los camaradas soviéticos- tenían en sus cascos de color café el símbolo de la IV Internacional. En sus manos llevaban mantas con consignas a favor de "la Rusia de Lenin y Trotsky".

Tras describir la escena a los lectores de Life, el periodista la "explicó" afirmando que los mineros bolivianos eran unos analfabetos que no sabian que Trotsky, para ellos un personaje casi mítico, había muerto dos décadas antes (John, 2016, pp. 239-240). Muy al contrario, sabian muy bien quién era Trotsky: sus ideas habian penetrado profundamente en los socavones. Entre los mineros bolivianos, "aprendi más acerca del trotskismo de lo que hubiera sido el caso en la mayoria de las escuelas de posgrado, especialmente en los Estados Unidos", relata la antropóloga June Nash, famosa por sus estudios de las comunidades mineras en las que recibió su iniciación en el marxismo (Nash, 2007, p. 20).

El haber producido "uno de los partidos trotskistas más influyentes y longevos del mundo" constituye "una de las curiosidades de Bolivia", escriben dos politólogos especializados en el país (Malloy y Gamarra, 1988, p. 59). Muchos han tratado el fenómeno como un aspecto pintoresco del paisaje, visión que tal vez a los mineros trotskistas de Siglo XX les habria parecido un síntoma del analfabetismo político de muchos "expertos". Sin embargo, al observar que en Bolivia "los marxistas disidentes... ganaron una influencia significativa, estableciendo una tradición trotskista más indeleble que en otras partes de América Latina", un pionero de los estudios latinoamericanos sugiere que esto se debe a que los trotskistas eran "más afines a las aspiraciones de los trabajadores bolivianos" que los partidarios de otras agrupaciones de izquierda (Whitehead, 1991, p. 528).

En repetidas ocasiones, a veces durante periodos extensos, el movimiento fue interlocutor, socio semivoluntario, espectro y rival para presidentes y partidos gobernantes. ¿En qué otro país consideraria el Presidente de la República que fuera necesario advertir al pueblo que un "gobierno trotskista" duraría poco tiempo, puesto que los países poderosos no lo tolerarian? En Bolivia, esa fue la advertencia que hizo en un discurso oficial el presidente Víctor Paz Estenssoro, jefe del Movimiento Nacionalista Revolucionario, en el segundo año de la Revolución Boliviana que lo había llevado al poder (Paz, 1954, p. 52).

Por su parte, las agencias gubernamentales norteamericanas y sus amigos en la gran prensa prestaron un nivel de atención sorprendente a las actividades y opiniones de los trotskistas bolivianos. Cuando una oleada de protestas sindicales sacudió al país a fines de los años 50, la revista Time (16 de marzo de 1959) señaló sarcásticamente: "Bolivia es la joya más brillante en la corona de la IV Internacional, agrupación de 
los "verdaderos" comunistas con su línea de "obreros del mundo uníos" y de oposición a los rojos de Rusia”.

\section{Orígenes}

La trayectoria del movimiento comenzó con un puñado de jóvenes bolivianos que se rebelaron en contra de un ancien régime en el que la minúscula élite "blanca" pisoteaba arrogante e impunemente a los mineros y campesinos indigenas de cuyo trabajo vivian. Entrando al torbellino de experimentación intelectual ecléctica de las primeras décadas del siglo XX en América Latina, estos activistas encontraron inspiración en incas y bolcheviques, el Amauta de Mariátegui, comunistas mexicanos y chilenos, aunque las obras de Trotsky eran de dificil acceso.

En el abismo de la Gran Depresión, su país entró en una crisis profunda y traumática. Convulsionada por el conflicto con Paraguay en la Guerra del Chaco (1932-1935), Bolivia experimentó una oleada de radicalización a fines de los años 30 . Los jóvenes "derrotistas" que alzaron la voz contra la carniceria fratricida, si no perecieron en el frente de batalla, enfrentaron la cárcel y el destierro.

El trotskismo boliviano nació como corriente con marcadas características específicamente nacionales. En su nacimiento participó el Grupo Tupac Amaru, basado en Argentina y dirigido por Tristán Marof (seudónimo del escritor bohemio Gustavo Navarro), que mezclaba elementos del ideario indigenista, aspectos del pensamiento marxista internacional y una fuerte dosis de nacionalismo romántico. El otro grupo, Izquierda Boliviana, basado en Chile, era dirigido por José Aguirre Gainsborg, que en el destierro había militado en la sección chilena de la Oposición de Izquierda internacional. En 1935, se fusionaron para formar el Partido Obrero Revolucionario.

Tras la casi desaparición del partido en una serie de crisis politicas (y con la salida de Marof y la muerte de Aguirre), el POR logró establecerse como organización funcionante, aunque en sus años formativos su relación orgánica con el trotskismo internacional fue tenue.

\section{La Tesis de Pulacayo y el protagonismo obrero}

Después de la Segunda Guerra Mundial, el crecimiento de la influencia trotskista fue frecuentemente reportado como índice del auge del radicalismo obrero. El símbolo más famoso y la encarnación documental más importante de aquélla ha sido la Tesis de Pulacayo, que el POR escribió para la Federación Sindical de Trabajadores Mineros de Bolivia (FSTMB) en 1946. Inspirada por la teoría de la revolución permanente, la Tesis -que llama a los mineros a dirigir a la gente pobre del campo y 
de la ciudad en una revolución social- no sólo estableció la "ideología oficial" de la Federación sino que "se constituyó en el sustento ideológico de la identidad minera" (Klein, 1969: 384; Cajías de la Vega, 2004, p. 58).

Entre los puntos más importantes de la Tesis estaban los que marcaron el rechazo tajante de la colaboración de clases: "Con la burguesía no tenemos que realizar ningún bloque ni ningún compromiso", enfatiza, al llamar a la "absoluta independencia" de los sindicatos con respecto a "los sectores burgueses, al reformismo de izquierda y el gobierno". "No podemos ni debemos solidarizarnos con ningún gobierno que no sea el nuestro propio, es decir obrero", recalca, al insistir:

El obrero que tiene la debilidad de cambiar su puesto de lucha en las filas revolucionarias por una cartera ministerial burguesa pasa a las filas de la traición. La burguesía idea a los ministros "obreros" para poder engañar mejor a los trabajadores... ${ }^{1}$

El impacto de la Tesis de Pulacayo fue tan grande que hasta Régis Debray, un acérrimo enemigo del trotskismo, la calificó como la "Carta Fundadora" del sindicalismo boliviano. Al fustigar a la clase obrera boliviana por lo que consideraba su "exagerada confianza en sí misma", el ex compañero del Che Guevara señalaba "la persistente tendencia trotskista entre los obreros de base", indicio de que "la teoría de la revolución permanente ganó autoridad y credibilidad con un gran sector del movimiento obrero" (Debray, 1975, pp. 43-44, 47, 58). Casi tres lustros después de la aprobación de la Tesis, el nivel de influencia del POR entre los trabajadores del subsuelo llevó al prominente intelectual boliviano René Zavaleta Mercado a quejarse de que, supuestamente, el dirigente trotskista Guillermo Lora "es a veces, dueño feliz de una dictadura porista sobre el proletariado minero" (Zavaleta Mercado, 1959: 3).

Tras la profunda escisión del trotskismo boliviano que se produjo a mediados de los 50 (ver más abajo), el sector dirigido por Guillermo Lora estableció una presencia especialmente fuerte en Siglo XX. El "otro" POR, encabezado por Hugo González Moscoso, se construyó una base importante entre los trabajadores de Catavi, Llallagua y otros centros mineros. En llamativos boletines mineros ya a finales de los 50 y comienzos de los 60 enfatizaba, entre otros temas candentes, el vínculo entre la lucha obrera y la liberación de la mujer e incentivó la formación de comités de amas de casa en los campamentos mineros. En esos años

1. "Tesis de Pulacayo" (noviembre de 1946), publicada en numerosas ediciones. Hay mucho más que decir acerca del tema, pero por falta de espacio, aquí y en algunos otros casos me permitiré remitir a los lectores a la discusión en John (2016, pp. 125-133, 239-241). 
jugó también un papel importante en el sindicato de maestros (Bravo Cladera, 2013, pp. 70-71). ${ }^{2}$

La insurrección del 52 aplastó al ejército, pero con el paso de unos años -y la ayuda del Pentágono- el régimen del "nacionalismo revolucionario" logró reconstruirlo. En 1964, René Barrientos, piloto del avión que llevó a Víctor Paz a la capital boliviana en 1952 -convertido en general, jefe de la fuerza aérea, favorito de Lyndon Johnson y vicepresidente del mismo Paz- lo derrocó e inauguró un nuevo ciclo de dictaduras militares. Bajo éstas, la heroica labor de organización de los cuadros poristas de ambas vertientes fue fundamental para la resistencia obrera. Frente a la embestida represiva, los dirigentes mineros trotskistas -entre ellos César Lora e Isaac Camacho, asesinados en 1965 y 1967, respectivamente- encabezaron la formación de "sindicatos clandestinos".

De nuevo en la década de los 70 , los activistas trotskistas jugaron un papel central en los comités de base que se reunieron dentro de las minas, saliendo para desafiar al dictador Hugo Banzer. En diciembre de 1977, la militante porista Aurora Villarroel de Lora propuso y jugó un papel central en la huelga de hambre de las mujeres de las minas que desató las movilizaciones de masas que pusieron fin al gobierno banzerista.

\section{Trotskistas quechuas "siembran pánico" entre los gamonales}

Si bien el trotskismo boliviano ha sido ampliamente conocido por su impacto en el movimiento obrero, un aspecto de su historia que frecuentemente se pasa por alto es la identificación de sus fundadores con la formulación y divulgación de ideas y consignas radicales sobre lo que se solía conocer como la "cuestión indígena". Otro es que su influencia se extendió a importantes sectores campesinos, a tal grado que llegó a ser, durante un periodo clave, obsesión de los gamonales (terratenientes) y voceros gubernamentales.

El énfasis en la importancia de las luchas indígenas y campesinas se remonta a los orígenes del trotskismo boliviano. Casi una década antes de participar en la fundación del POR, Tristán Marof popularizó el lema de "Tierras al indio, minas al estado" en su libro La justicia del Inca (1926). A mediados de 1927, apoyó la sublevación indígena de Chayanta, Potosí. Junto con su supuesto involucramiento en un "complot comunista" contra el gobierno, esto llevó a su confinamiento y luego al exilio.

2. En la década del 80 el equipo de activistas del POR-Masas (orientado por Lora) encabezado por Vilma Plata se hizo famoso como dirección del sindicato de maestros de La Paz. 
En su libro más influyente, La tragedia del altiplano (1934), Marof defendió la rebeldía indígena contra el racismo endémico de la sociedad boliviana a la vez que denunciaba el "pongueaje" (sistema de servicio obligatorio al gamonal) y el robo de tierras campesinas. Junto con su agitación contra la Guerra del Chaco, esto explica en gran parte el prestigio del que gozaba Marof -a pesar de su reputación (merecida) de aventurero- cuando ayudó a fundar el POR en 1935.

Por otra parte, la primera escuela indigenista de Bolivia -la "escuela-ayllú" de Warisata- se estableció y desarrolló en gran parte debido a la labor de personajes vinculados con el trotskismo. Ex miembros de la Izquierda Boliviana de Aguirre y el Grupo Tupac Amaru, algunos participaron en la fundación del POR. Otro, el artista y polemista Carlos Salazar Mostajo, llegó a ser uno de los publicistas y defensores más importantes de Warisata (Salazar Mostajo, 1997).

Sin embargo, la influencia del trotskismo en el campo se arraigó en gran parte por la vía minera. Cuando en las minas se daban las "masacres blancas" (despidos en masa), muchos trabajadores que volvian a sus pueblos natales llevaban consigo su entrenamiento sindical (impartido a veces directamente por los trotskistas). Así nació un número significativo de sindicatos campesinos.

En el Valle de Cochabamba surgió un importante núcleo de trotskistas quechuas, centrado en el pueblo de Ucureña, que se dedicó a organizar sindicatos y grupos de autodefensa entre los campesinos. En 1953, la gran prensa -tanto la oficialista de La Paz como la de la derecha cochabambina- se llenó de titulares contra los "dirigentes trotskistas" y "militantes poristas" que "sembraron pánico" al dirigir una oleada de tomas de tierra, acompañadas por el "secuestro de armas en haciendas". ${ }^{3}$ En contra de los trotskistas campesinos de Cochabamba las "guardias blancas" de los gamonales desataron un reino de terror, que el gobierno emenerrista suplementó con detenciones, encarcelamientos y la formación de una nueva capa de burócratas rurales a sueldo (John, 2016, pp. 190-201).

Tras las tomas de tierras en el valle de Cochabamba, el gobierno llevó a cabo lo que, a pesar de su carácter limitado y moderado, constituyó una de las principales medidas de la Revolución Boliviana: la reforma agraria. "Fue sin duda un paso más dado por la presión indígena y campesina que por la convicción del gobierno del MNR" (Ticona Alejo,

3. En realidad, los militantes cochabambinos propugnaban una línea mucho más a la izquierda que la de la dirección nacional del POR. Ésta participaba oficialmente en la comisión de reforma agraria del gobierno, mientras que los de Cochabamba buscaron realizar la "revolución agraria". Este grupo de activistas llegó a formar su propia fracción dentro del POR (ver más abajo). 
2003: 289). En realidad, ese partido formado por una fracción de la elite boliviana nunca había luchado por tal cosa. Es significativo que en el "Día del Indio" (2 de agosto de 1953), el decreto fuera firmado, bajo la mirada de 100.000 campesinos, en Ucureña, cuna de las movilizaciones campesinas en las que los trotskistas quechuas habian jugado un papel crucial.

\section{Presencia cultural}

Según René Zavaleta Mercado -que ya para los años 70 se había convertido en izquierdista-, al hablar del proletariado boliviano, cuya columna vertebral era el sector minero, había que reconocer que "se trata de una clase dotada de mejor sentido histórico que todos sus iguales en el continente" (Zavaleta Mercado, 1974, p. 84).

Al luchar por establecerse como referente en el mundo minero, los trotskistas bolivianos creían que junto a la rica producción cultural de las mayorias nacionales, despreciada y descartada por la elite durante siglos, la memoria colectiva que los mineros apreciaban ayudaria a enriquecer la conciencia obrera en todo el mundo. En Bolivia, como en otros lugares donde el sector minero ha jugado un papel crucial en el movimiento obrero, las canciones mineras han sido fundamentales en la transmisión y conservación de la memoria colectiva de las luchas proletarias. Entre ellas figuran muchas sobre las masacres mineras, la lucha contra capitalistas e imperialistas sinvergüenzas que condenan al obrero a morir escupiendo sangre por el mal de mina (silicosis), y sobre la Tesis de Pulacayo también.

El trotskismo boliviano conquistó una presencia especialmente importante en el campo de las artes plásticas. Desde sus inicios fue caracterizado por el poder llamativo de las imágenes que figuraban como parte integra de su propaganda. Muchas fueron obra de Miguel Alandia Pantoja, que llegó a ser el muralista más importante del país y fue un dirigente tanto del POR como de la Central Obrera Boliviana (COB), que ayudó a fundar en abril de 1952. Los murales revolucionarios que pintó en edificios gubernamentales, así como su amistad con presidentes emenerristas, encarnan algunas de las contradicciones políticas características del trotskismo boliviano.

Además de su trabajo relacionado con la escuela-ayllú de Warisata, Carlos Salazar Mostajo fue pintor e historiador del arte. También fundó la Liga Socialista Revolucionaria, que aunque nunca llegó a tener una militancia numerosa, presentó un punto de vista distintivo como corriente dentro del movimiento trotskista. ${ }^{4}$

4. Ver Salazar Mostajo (2003 y 1989). De particular importancia fue la crítica de la 
A lo largo de su historia, comenzando con su generación fundadora, miembros y simpatizantes del movimiento trotskista se destacaron también en los campos de la literatura, la crítica, la bibliotecología y otros aspectos de la cultura boliviana. En 1970, el POR de Lora ganó un lugar importante en el movimiento estudiantil mediante la "Revolución Universitaria" que se inició en la Universidad Mayor de San Andrés.

\section{¿Cómo se explica?}

A comienzos de 1929, exilado de la URSS por órdenes de Stalin, León Trotsky se refugió en la isla turca de Büyükada, conocida en aquel entonces como Prinkipo. Expulsado de un país tras otro, pasó sus últimos años en Coyoacán, México, donde fue asesinado en 1940 por el agente estalinista Ramón Mercader. Poco después, entre los "chorros" de dinamita que formaban parte de la cotidianeidad minera, ya comenzaban a penetrar en las minas bolivianas conceptos centrales del programa político que el nombre de Trotsky evocaba, que retumbarian en los años siguientes.

Es llamativo que ideas asociadas con el desterrado organizador del Ejército Rojo hicieran el viaje de Prinkipo a Pulacayo. No es una exageración subrayar que al abordar el surgimiento del trotskismo boliviano, así como el extenso y duradero impacto que ha tenido, se trata de "un fenómeno único y excepcional" en la historia del radicalismo latinoamericano (Goldenberg, 1971: 96).

Para entender este fenómeno, es preciso en primer lugar apreciar la fuerza especial, en la Bolivia de los años 40, de dichas ideas. A los mineros bolivianos de la época de la Tesis de Pulacayo no les parecía exótica una teoría revolucionaria que justificara y explicara el papel de vanguardia en las luchas populares que ellos ya habian comenzado a jugar. Allá en los oscuros socavones, donde el "desarrollo desigual y combinado" se reflejaba en vocablos como mita, block caving, ch'alla, perforadora y huallpa-chaki, ${ }^{5}$ los conceptos de la revolución permanente ayudaron a los mineros a entender el mundo en el que vivían, a dar significado a su vida y a orientar sus luchas.

El "trotskismo" les decía que ese mismo desarrollo desigual y combinado -incluso la despiadada explotación que conllevaba-colocaba en

corriente de Salazar con respecto a ciertos aspectos de la Tesis de Pulacayo y sus advertencias sobre la naturaleza y perspectivas de la Asamblea Popular en 1971.

5. Mita: una jornada laboral o el pago correspondiente (originalmente: sistema de trabajo obligatorio del imperio incaico, adoptado en Alto Perú por los españoles); block caving: un método de minería subterránea; ch'alla: acto de reciprocidad u ofrenda a la Pachamama o al "tío de la mina"; huallpa-chaki (pata de gallina): un método de perforar. 
sus manos la fuerza potencial, las herramientas y armas sociales con las que podian encabezar la liberación de todos los explotados, que sería también la de su país; y que su suerte se vinculaba a la vez con la de los obreros y oprimidos del mundo entero.

Así, la atracción de las ideas trotskistas reflejaba, en parte, la centralidad del proletariado minero en un país que dependió por largo tiempo de una sola mercancía: el estaño. A comienzos del siglo XX, este "metal del diablo" se convirtió en materia estratégica a nivel mundial, debido en gran parte a su uso en el suministro de alimentos y armamentos para los grandes ejércitos. Reclutados de las aldeas campesinas indígenas, los mineros adquirieron un "peso específico" excepcionalmente grande en la vida nacional. Centrado en la Federación Minera fundada en 1944, el movimiento obrero boliviano se convirtió en uno de los más politizados y audaces del hemisferio.

Concentrados en los campamentos del altiplano, los mineros jugaron un papel militar decisivo en la Revolución Nacional de 1952, una de las convulsiones sociales más profundas del siglo XX latinoamericano. El impacto regional de esta revolución debió mucho a la prominencia política de los mineros y campesinos indígenas en la destrucción del viejo orden y la conflictiva construcción de sus sucesores.

\section{Bolivia, Vietnam, Ceilán}

¿Qué tenía en común Bolivia, entonces, con Vietnam y Ceilán? Se trata de sociedades muy distintas; además, si bien había minas en Indochina, ni allí ni en Ceilán existía un proletariado minero con el mismo tipo de peso o papel social como fue el caso en Bolivia.

Sin embargo, fue en estos tres países donde la corriente trotskista llegó a tener un alto grado de influencia, a nivel nacional, durante un periodo extenso.

Bolivia: Es importante señalar que el POR surgió cuando en Bolivia no había un Partido Comunista cohesionado. Su fundación ocurrió cinco años antes que la del Partido de la Izquierda Revolucionaria (PIR), de orientación estalinista, que se estableció en 1940; el PC oficial se fundó sólo en 1950. Tras causar una sensación nacional en 1946 con la Tesis de Pulacayo, el POR fue durante años tema de noticias y denuncias en la prensa diaria. Llegó al parlamento en 1947 (como parte del Bloque Minero Parlamentario) y fue un punto de referencia fundamental durante la Revolución Nacional. Nunca fue un partido de masas, vivió décadas a la sombra del MNR, y se dividió en "dos POR" con la convulsiva crisis interna de 1954-1955. Sin embargo, el trotskismo siguió jugando un papel vital en los movimientos sociales durante más de medio siglo.

Vietnam: La Oposición de Izquierda Indochina, afiliada con la Opo- 
sición internacional de Trotsky, se estableció en 1929, el mismo año en que se fundó el PC Indochino estalinista (Van, 1995, pp. 11, 15). Los trotskistas vietnamitas -organizados principalmente en el grupo La Lutte y la Liga de Comunistas Internacionalistas- establecieron una base sólida y numerosa en la clase obrera de Saigón; su influencia se extendió a otras partes de la colonia y a sectores del campesinado. En un período en que el imperio francés era administrado por el Frente Popular, el dirigente más famoso del movimiento trotskista vietnamita, Ta Thu Thau, fue una figura central en la lucha contra el colonialismo. Al final de la Segunda Guerra Mundial, el movimiento trotskista tenía miles de afiliados. Al rechazar el acuerdo del gobierno francés con el Viet Minh de Ho Chi Minh, participó en el levantamiento de septiembre de 1945 contra la reintroducción de tropas francesas; como represalia, fue aniquilado por las fuerzas estalinistas.

Ceilán: En esta colonia británica, cuya economía se centraba en gran parte en la exportación del té, el movimiento trotskista surgió de una manera distintiva. Considerado el primer partido moderno de la historia ceilanesa, el Lanka Sama Samaja Party (LSSP) se organizó en 1935, originalmente como una agrupación socialista "genérica". En su dirección había simpatizantes tanto de Stalin como de Trotsky, hasta que la mayoría trotskista tomó control del partido de forma definitiva en 1939-1940 (Ervin, 2006, pp. 75-76). Durante décadas el LSSP -y por un período en los años 40 , su desprendimiento más radical, el partido Bolchevique Leninista- fue protagónico en la lucha independentista y sindical, encabezando además el movimiento de huelgas y protestas masivas conocido como el Hartal de 1953. También tuvo una fuerte presencia parlamentaria. ${ }^{6}$

En los casos de Bolivia, Vietnam y Ceilán, entonces, hay que destacar que el núcleo central del proletariado se politizó cuando imperaban dos factores clave: a) no había un partido comunista ya cohesionado con fuertes raíces en el movimiento obrero; b) la Internacional Comunista ya había proclamado y generalizado la política del frente popular. En la práctica, durante este período formativo, el frente popular significaba aceptar la subordinación a los amos imperialistas y sus representantes locales. Por lo tanto, existía un espacio político y un campo de acción excepcionalmente amplio para los organizadores trotskistas. A continuación, veremos cómo esto se manifestó en el caso boliviano.

6. El peso del parlamentarismo en la vida partidaria del LSSP contribuyó a que se distanciara cada vez más del trotskismo, y en 1964 entró al gobierno de coalición encabezado por el partido nacionalista cingalés de Sirimavo Bandaranaike. 


\section{El precio del estaño}

Este es el título de la renombrada novela sobre la Masacre de Catavi de 1942 que, cuando se publicó en el octavo año del gobierno emenerrista, recordaba a los lectores que este precio se pagaba en sangre minera (Taboada Terán, 1960). A la vez, la frase refleja un tema fundamental en la historia del sojuzgamiento de Bolivia al imperialismo. La Reconstruction Finance Corporation, entidad del gobierno norteamericano creada durante la Gran Depresión, fue "armada con el mandato del Congreso [de Estados Unidos] para conseguir estaño barato y asignarlo a la industria privada", con lo cual, durante años, "trabajó celosamente con el propósito inquebrantable de bajar el precio" del metal (Dorn, 2011: 206).

Este esfuerzo se convirtió en una cuestión de "precios democráticos" (sic), cuando, el 11 de diciembre de 1941, Estados Unidos declaró la guerra contra Alemania. ${ }^{7} \mathrm{Al}$ otro día, un decreto del gobierno boliviano del general Enrique Peñaranda prohibió todo acto que pudiera disminuir o afectar la producción de minerales.

Casi exactamente un año después, estalló la huelga contra la empresa Patiño Mines en Catavi y Siglo XX. Para suprimirla, el gobierno ejecutó la matanza del 21 de diciembre de 1942. Como subrayó la prensa trotskista norteamericana, el Departamento de Estado y el embajador norteamericano habian "presionado al gobierno de Peñaranda para que mantuviera a los mineros en condiciones de hambre y servidumbre" y después de la masacre, "el carnicero Peñaranda visitó los Estados Unidos, donde fue festejado por Roosevelt en la Casa Blanca y fue saludado en la prensa capitalista como un campeón de la democracia". ${ }^{8}$

El gobierno de Peñaranda intentó culpar al PIR por la huelga de Catavi. Sin embargo, la política estalinista según la cual la clase obrera debía hacer causa común con Roosevelt, Churchill, junto con los Peñaranda, Batista, Trujillo et al., como expresión de un supuesto frente democrático, tenía pocas posibilidades de prosperar en el sector minero, que ya era la punta de lanza de la radicalización del proletariado boliviano.

Para los jóvenes activistas del POR, la huelga de Catavi abrió nuevas perspectivas para trasmitir las ideas de la revolución permanente mien-

7. Como se remarcó en una audiencia del Comité sobre Servicios Armados del Senado de Estados Unidos en 1979, "Los bolivianos recuerdan que Estados Unidos adquirió su reserva estratégica de estaño como contribución de un "aliado en defensa de la democracia" durante la Segunda Guerra Mundial y la Guerra de Corea" (Committee: 1979, p. 44).

8. The Militant (Nueva York), $1^{\circ}$ de enero de 1944. En la Casa Blanca el 5 de mayo de 1943, el ministro boliviano de Relaciones Exteriores que acompañaba a Peñaranda reportó a Roosevelt: "Bolivia está realizando un esfuerzo máximo para suministrar el estaño" para Estados Unidos y sus aliados (Foreign Relations, 1965, p. 561). 
tras realizaban peligrosas labores de solidaridad con los trabajadores frente a la represión.

Mientras tanto, en el parlamento, quien cobró fama por su intervención sobre el asunto de la masacre fue un ex abogado de la empresa Patiño convertido en dirigente del flamante MNR (fundado en junio de 1942): el diputado nacional Víctor Paz. Este partido nacionalista establecido por un sector joven de la elite boliviana no tenía bases de apoyo en los campamentos mineros, pero comenzó a establecerlas cuando a fines de 1943 el coronel Gualberto Villarroel derrocó a Peñaranda e invitó al MNR a integrar su gabinete. Fue bajo el gobierno de Villarroel, y con el apoyo de éste, que se fundó la FSTMB en 1944. Como dirigente central de la Federación, se eligió a Juan Lechín, ex empleado de mina que el año anterior el MNR había nombrado subprefecto de la zona Catavi-Siglo XX.

En julio de 1946, Villarroel fue derrocado y ahorcado frente al palacio presidencial entre protestas auspiciadas por el PIR y la Rosca (denominación popular para referirse a la elite minera y política). El "presidente colgado" tomó su lugar en el imaginario histórico del nacionalismo boliviano mientras se inauguró el "sexenio rosquero" de represión brutal contra el movimiento obrero y la izquierda. ${ }^{9}$

Cuando con sangre de nuevo se cotizó el precio del estaño en una nueva masacre de mineros, la de Potosí en enero de 1947, el Ministro del Trabajo que ordenó la entrada del ejército a la zona minera era pirista, como también lo fueron el prefecto y el jefe de policía de Potosí.

\section{Una alianza y su precio}

Ya para ese entonces, los jóvenes activistas del movimiento trotskista habian escrito una nueva página en la historia del movimiento obrero con la aprobación de su Tesis de Pulacayo. Los lectores de la gran prensa se acostumbraban a ver la palabra trotzkista (como los diarios solian escribirla) en los titulares. Junto con Lechín y otros dirigentes de la FSTMB, Lora y cuatro poristas más fueron elegidos al parlamento a comienzos de 1947, como integrantes del Bloque Minero Parlamentario, del cual Lora fue nombrado coordinador. La influencia del trotskismo boliviano se hacía sentir.

Sin embargo, esta influencia tenía su precio: fortalecer la imagen combativa del ala laboral del MNR. Lechín y otros voceros de lo que se conocería como la "Izquierda" emenerrista jugaron un doble juego,

9. El POR no tuvo una línea unitaria a escala nacional sobre los sucesos, pero en La Paz participó en el levantamiento contra Villarroel que abrió paso a la derecha; no parece haberse realizado una sistemática evaluación de la experiencia. 
mostrando una cara radical en algunas circunstancias a la vez que buscaban agrandar la autoridad del MNR. Las metas de este partido nacionalista eran muy distantes de aquellas del socialismo marxiano y fue profundamente hostil al principio de la independencia politica del proletariado pregonado en la Tesis de Pulacayo.

A la vez que Lechín "jugó un papel lleno de ambigüedades", en palabras de Hugo González Moscoso: "toda la dirección [del POR] que actuaba en La Paz, y sobre todo en Oruro" fungía como equipo de asesores de Lechín. Si bien Lora fue el principal de estos asesores, como muestran sus escritos sobre este período, el propio González se incluyó a sí mismo en la descripción (John, 2016, pp. 121-122).

En este bloque político de largo alcance, el POR ayudó a dar a Lechín una imagen más revolucionaria, con lo cual el partido nacionalista obtenía la mayor parte del beneficio político. Sin embargo, este periodo de ascenso de la influencia del trotskismo boliviano sentaria una pauta que marcaría muchas de las fases más criticas de su historia.

Al estudiar el periodo 1950-1951, se observa una y otra vez que la adaptación a la izquierda del MNR afectaba el arsenal de conceptos con el que el trotskismo boliviano enfrentaria los enormes retos planteados por la Revolución del 52.

Para Trotsky, era crucial establecer que la táctica del frente unido (traducido a veces como "único") significaba una acción realizada conjuntamente entre el partido revolucionario y otras fuerzas, para un objetivo limitado y determinado, no un bloque programático. Recalcó -notablemente en sus escritos sobre el desastroso bloque del PC chino con el Kuomintang burgués- que "la regla más importante" era "no confundir las banderas" con las de otros partidos.

En contraste, en el período anterior a la Revolución Nacional, el POR iba profundizando, sistematizando y teorizando el patrón de hacer un bloque político -o una serie de bloques- con el ala laboral del MNR que Lechín encabezaba. A la vez, buscaba extenderlo al conjunto del MNR. En 1950, por ejemplo, el POR integró el "Comité Cuatripartito" con el MNR, el PIR y el Partido Comunista (formado ese año mediante una escisión del PIR), buscando establecer una plataforma común en aras de establecer un "frente antiimperialista", cosa que no logró aunque la izquierda del MNR se mostró interesada. En 1951, el POR lanzó repetidos llamados al MNR a formar dicho frente y a definirse como partido favorable a los explotados.

Durante años y a pesar de las duras críticas que el POR también dirigía contra el MNR, los trotskistas bolivianos habian mezclado o confundido las banderas con los emenerristas de "izquierda" en el movimiento sindical, en el parlamento, en los discursos y documentos que escribian para Lechín, en las alabanzas que a veces le dirigian en su 
prensa, etcétera. Ahora, se agregaba un nuevo factor: la dirección de la IV Internacional, encabezada por Michel Pablo, indicó que en el caso de una movilización de masas impulsada por el MNR, la sección boliviana deberia ayudar a llevarla "incluso hasta la toma del poder por el MNR, sobre la base del programa progresivo del frente único antimperialista". Además, declaró, esto podría abrir paso al lanzamiento de "la consigna por la formación de un Gobierno Obrero y Campesino constituido por ambas organizaciones..."10

¿Qué tipo de partido era el MNR, entonces? El tema de su "naturaleza de clase" podía parecer muy "teórico" hasta la hora de la verdad, que podría ser muy tarde cuando urgia la claridad. Estas cuestiones no eran de cogitación pura; se entrelazaban con la forma de hacer política frente a Lechín y la dirección sindical, que eran el vínculo clave entre el partido nacionalista burgués y las masas. Tras la llegada del MNR al poder, el precio de la confusión subió cada vez más.

El MNR no pensaba realizar ninguna revolución. Más bien, articuló una más de las conspiraciones golpistas con un sector castrense que eran su especialidad. Esta vez, el plan incluía al jefe de los carabineros y la ultraderechista Falange Socialista Boliviana. Cuando el MNR ganó los comicios de 1951 y el gobierno se rehusó a respetar los resultados, el plan putschista se puso en acción para el 9 de abril de 1952.

Sin embargo, frente a la inesperada resistencia del ejército y la creciente participación de sectores de masas, tanto la FSB como el jefe de los carabineros desertaron. Hernán Siles Zuazo, "subjefe" del MNR y encargado de sus fuerzas -el exiliado Paz Estenssoro estaba en Argentina-, buscó arreglar un gobierno conjunto con los militares y acordó una tregua con el jefe del alto mando militar. La situación cambió fundamentalmente cuando, frente al avance del ejército a La Paz, la población civil realizó una serie de combates que se convirtieron en una verdadera insurrección.

\section{"La Revolución Boliviana, entre Wall Street y Trotsky"}

La Tesis de Pulacayo había insistido que los mineros -a pesar de ser una clase minoritaria- iban a encabezar a las masas explotadas de la ciudad y del campo en el asalto revolucionario que se necesitaba para derrocar a la odiada Rosca. Desde los orígenes del movimiento trotskista boliviano, sus activistas cifraban sus esperanzas en la combinación de un levantamiento proletario y una guerra campesina para arrasar con el viejo orden. Para los políticos y partidos que se oponían al programa

10. "Resolución sobre América Latina", Cuarta Internacional (Buenos Aires), agosto-septiembre de 1951, pp. 60-61. 
de la revolución permanente, se trataba de un delirio, un sueño utópico o una receta sectaria.

En las Jornadas de Abril de 1952, el sueño de unos y la pesadilla de otros bajó de las minas, emergió de los barrios obreros y se levantó en las calles de La Paz y Oruro. Las batallas callejeras se transformaron en insurrección cuando los mineros bajaron a La Paz a combatir hombro a hombro con los fabriles. En El Alto, asediaron y derrotaron a las fuerzas gubernamentales. En Oruro, tomaron el cuartel y en plena batalla derrotaron al ejército.

Después de los resultados definitorios de la jornada del 10 de abril tanto en La Paz como en Oruro, las fuerzas populares de la insurrección habían derrotado a las tropas del Ejército regular. No fue una victoria relativa: la victoria sobre los militares fue aplastante. (Murillo, 2011, p. 135) ${ }^{11}$

Después de que los mineros tomaron el Palacio Quemado, Lechín lo entregó a Siles. Víctor Paz volvió de Buenos Aires (en un avión piloteado por René Barrientos) para ocupar la silla presidencial.

Los cuadros trotskistas habian luchado con enorme valentia en la insurrección, jugando un papel importante, por ejemplo en la toma del arsenal de La Paz y en la derrota de los militares en Oruro (John, 2016, pp. 173-178). Lo hicieron a pesar de la falta de una dirección centralizada en aquellos momentos, situación provocada en gran parte por la represión. La verdad es que el POR no estaba en condiciones de tomar el poder en sus propias manos en abril de 1952 - pero sí podía haber representado un polo de atracción importante al desarrollar clara y sistemáticamente una política basada en la independencia revolucionaria del proletariado.

El potencial se puede apreciar en el titular con el que el diario parisino Le Monde (24 de octubre de 1953) resumía la disyuntiva de la Revolución en Bolivia: "La Revolución Boliviana entre Wall Street y Trotsky". Sin embargo, la orientación desarrollada por la dirección porista -en los días, meses y años que siguieron a las Jornadas de Abril- reforzaba las ilusiones de las masas frente al gobierno del MNR.

La historia del POR se ha conocido en gran parte debido a las obras de Guillermo Lora. ${ }^{12}$ Muchas veces se cree que la posición del partido

11. La historiografia de estas jornadas ha sido enriquecida con la obra de Mario Murillo basada en detalladas entrevistas con veteranos de estos combates (Murillo, 2011).

12. La versión de Lora se sintetizó y popularizó en la serie de artículos de Política Obrera (Buenos Aires), "La Historia del POR boliviano", publicada entre octubre y diciembre de 1974 (disponible en línea: marxists.org/espanol/tematica/kiosko/ argentina/politica_obrera). 
en 1952 se impuso en contra de Lora o que consistió en una desviación de un sector de la dirección partidaria respecto de la línea del partido sostenida hasta ese momento. En realidad, representó la posición de la dirección en su conjunto, elaborada en gran parte por Lora, y fue la continuación y el resultado de la pauta de hacer bloques con el ala lechinista del MNR que había sido central en la vida del POR durante años.

La Central Obrera Boliviana se formó una semana después del triunfo de la insurrección, siguiendo la propuesta de Alandia Pantoja. Cuadros del POR ocuparon varios puestos clave en su dirección.

La Tesis de Pulacayo había declarado la guerra sin cuartel a la mera idea de "ministros obreros". Sin embargo, Lechín y el dirigente fabril Germán Butrón integraron el gabinete de Paz ostentando el título de "ministros obreros". Era crucial para el MNR utilizarlos para controlar a las masas en una situación de enormes esperanzas revolucionarias, en la que su gobierno descansaba, por decirlo así, en las bayonetas de las milicias mineras.

En el acta de fundación de la COB, el Primer Voto Resolutivo "RESUELVE: Ratificar a los compañeros Juan Lechín O. y Germán Butrón la absoluta confianza de la clase obrera y reafirmar su solidaridad y apoyo en los cargos ministeriales que actualmente ejercen".

Poco después, la prensa trotskista francesa y norteamericana publicó la entrevista a Guillermo Lora con la que el movimiento mundial pudo conocer la línea del POR sobre los acontecimientos. Lejos de rechazar la entrada de "ministros obreros" al gobierno, la saludaba diciendo que los trabajadores habian obligado a la derecha del MNR a "aceptar en el nuevo gabinete a los elementos obreros, que constituyen en el mismo la fracción de izquierda", que el POR "apoya la fracción de izquierda del nuevo gabinete" y rechaza "el delirio de una lucha contra el MNR". ${ }^{13}$

Estas posiciones se expresaron igualmente en los informes internos, en los llamamientos públicos a formar el "Frente Unico Anti-Imperialista [...] para la lucha conjunta" entre el POR y el MNR, en las declaraciones de que "el MNR es un partido en transición [...] a la nueva política de transformación revolucionaria", etc. Aquí no era cuestión de luchar militarmente contra intentonas golpistas o ataques imperialistas, sino que el POR daba un apoyo político (apoyo crítico, se lo suele calificar) al gobierno nacionalista.

Mientras tanto, el apoyo a la Izquierda lechinista fue bien concreto. La vieja pauta se reafirmó, a pesar de que Lechín ya era ministro: los dirigentes poristas lo asesoraban y redactaban sus discursos. No se

13. La entrevista se publicó primero en La Vérité (París), 17 de abril-7 de mayo de 1952, luego en The Militant. Décadas después, Lora recalcó "la verdadera importancia" de la entrevista como "anunciación del programa trotskysta" (Lora, 1978, 2, p. 237). 
puede entender el contexto real de las consignas como "Todo el poder a la Izquierda"14 $\sin$ apreciar esta realidad. No existe un mecanismo para medir el impacto de la politica del POR al reflejar y a la vez reforzar las ilusiones de las masas en al ala lechinista del MNR. Lo que sí sabemos es que Lechín ató a las masas al gobierno nacionalista que colaboró con el imperialismo contra los trabajadores, restableció el ejército y abrió el camino para la vuelta de éste al poder.

\section{¿Autocrítica?}

Para la historiografia de la izquierda, el debate de los temas históricos reviste especial relevancia cuando su interpretación se relaciona con cuestiones clave de la revolución y la contrarrevolución. Por lo tanto, me parece importante mencionar parte de una reseña del libro El trotskismo boliviano en la que el historiador argentino Juan Luis Hernández enumera varias de las observaciones que se hacen ahí sobre la línea política que el POR planteó durante la Revolución del 52 (Hernández, 2017, p. 44). ${ }^{15}$

Argumenta el colega Hernández: "Años después, los errores señalados fueron reconocidos por el propio Guillermo Lora, en una autocrítica quizás incompleta, pero que Sándor John pasa por alto (Lora, 1963: 38-39)". He reproducido la referencia tal como aparece en la reseña, por tratarse de una sección especial -titulada "Errores del POR"- de la importante obra La Revolución Boliviana del dirigente porista. Puede ser de hecho provechoso indagar acerca de lo que implicaba para el futuro del movimiento trotskista la definición de errores planteada ahí.

Veamos entonces lo que escribe Lora en dicha sección. Señala que la represión policíaca durante el sexenio rosquero había causado estragos en el partido, factor importante en la "debilidad numérica y organizativa del POR" durante el alzamiento, que "también contribuyó al fortalecimiento del MNR". De esto no cabe duda.

Lora continúa al afirmar que el "error más grande que cometió el POR radica en que no estuvo presente como Partido en las jornadas de abril", aunque sus cuadros intervinieron "en forma aislada". También indica que el POR debía haber lanzado la consigna de ocupación de las minas en 1952.

14. El POR también exigió "mayoría obrera" en el gabinete y anunció con júbilo en agosto de 1953 que la COB había decidido "que las personas que integren los ministerios en representación obrera, lo harán sujetos a un programa especialmente aprobado por la COB", etc.

15. Una versión más extensa de la reseña fue publicada en Archivos, año VI, $\mathrm{n}^{\circ} 12$ (marzo de 2018), pp. 165-168. 
He aquí el resto de la referida sección "Errores del POR":

La llegada del MNR al poder tuvo un efecto nefasto sobre los cuadros pequeño burgueses del Partido, que comenzaron a justificar el programa movimientista y preparar desde el primer día la traición que más tarde adoptaría el nombre de "entrismo".

Inmediatamente después del 9 de abril surgen en el POR toda una serie de teorías seguidistas. Unas sostenian que el MNR llegó a ocupar prácticamente el lugar del POR, como vanguardia proletaria; otras insinuaban que el POR era sólo una rama del MNR y que le correspondia apoyarlo incondicionalmente, evitando toda posible crítica. Y no faltaban los ilusos que soñaban con un milenario régimen movimientista. Todas estas tendencias eran producto de la desesperación y del miedo. La escisión del POR estaba planteada ya el 9 de abril y el posterior desarrollo de los acontecimientos la convirtió en inevitable. (Lora, 1963: 38-39)

Esto difícilmente se puede considerar como una autocrítica. No aborda las cuestiones fundamentales respecto a la línea oficial del POR, seguida durante años y expresada reiteradamente en el periódico oficial, los congresos, los documentos y las consignas oficiales del partido cuando Lora fue figura central de la dirección (junto con los que luego descartó como ilusos, pequeñoburgueses, etc.) y en muchos casos fue autor de los mismos. Uno de los hechos más importantes es que en la gran lucha interna de 1954-1955, la fracción de Lora y Edwin Möller se basaba explícitamente en la tesis de la X Conferencia del POR (1953), que planteaba que el "predominio total" de la izquierda del MNR transformaria al partido oficialista, con lo cual "podría hablarse de un posible gobierno de coalición del POR y del MNR que sería una forma de realización de la fórmula "Gobierno Obrero-Campesino".

Junto con esta perspectiva fantasiosa se reafirmó que la lucha debía "girar alrededor" de la consigna "Control total del Estado por la izquierda del MNR". El mismo año, Lora escribió un folleto para "la estructuración de un programa" del MNR, que se reproduce en sus Obras completas (Lora, 1995, pp. 187-246). Siguiendo esta lógica, fue la fracción Lora-Möller la que preparó el escenario para el "entrismo" en el MNR. Casi toda la fracción lo realizó, menos Lora, que a último momento se encontró "solito", como dicen los veteranos de la experiencia.

Muchos creen que por su alineamiento internacional con Michel Pablo, la fracción de González hizo el "entrismo", pero en realidad se opuso furiosamente a la propuesta. Mientras tanto, en Cochabamba, una tercera agrupación -pequeña y pronto destruida por la represiónargumentó que tanto la fracción de Lora como la de González sembraban 
ilusiones en el régimen del MNR, y que para poder orientarse frente a éste, era fundamental precisar que se trataba de un partido burgués, no "pequeñoburgués" como afirmaban los documentos oficiales del partido escritos y apoyados por Lora, González y el resto de la dirección (John, 2016, pp. 178-216).

No se realizó, en efecto, un verdadero balance, sobre la base de los documentos y la experiencia real del período antes, durante y después de abril de 1952. Y lejos de superada, la pauta se vio repetida, una y otra vez, de una u otra forma.

Las implicaciones se hicieron sentir con particular fuerza en 19701971, cuando -durante el gobierno del general "progresista" J.J. Torres- el POR de Lora jugó un papel central tanto en el Comando Político de la COB -tras entablar negociaciones acerca de la posible proporción de "ministros obreros" en el gabinete (hasta que Torres retiró la oferta)- como en la Asamblea Popular que el Comando convocó. ${ }^{16}$ El POR de González, habiéndose plegado a la estrategia guevarista, estuvo al margen de estos acontecimientos.

La dolorosa e imprescindible labor de asimilar la experiencia de este período ha sido obstaculizada por la persistente mitificación de esta Asamblea - que tras debates estériles, declaró un receso de más de dos meses mientras la derecha preparaba el "golpe anunciado" de agosto de 1971. Pero "era idea generalizada -compartida hasta por nosotros marxistas- que las armas serían cedidas por el equipo militar gobernante" (Lora, 1972: 97).

Desarmadas política y militarmente, las masas sufrieron otra terrible derrota. No obstante, con "los nacionalistas con charreteras" -entre ellos el depuesto Torres- y con los lechinistas y otros más, el POR de Lora formó el Frente Revolucionario Antimperialista, con el propósito declarado de "estructurar el gobierno del pueblo" e incluso alcanzar el socialismo (ver John, 2016: 274-294). Tales bloques y concepciones no salieron de la nada.

Al esbozar sólo algunos de los temas polémicos de la historia del trotskismo boliviano, espero ayudar a alentar el estudio, análisis y debate de ésta, una de las venas más ricas de la historia del movimiento obrero y de izquierda en América.

16. Según el Comando (declaración del 15 de enero de 1971), la Asamblea tendría "facultades de fiscalización del gobierno nacional y de iniciativa en materia legislativa" (luego se le aplicaron etiquetas más radicales). 


\section{Bibliografía}

Bravo Cladera, E.N. (2013). Elsa Cladera de Bravo: Maestra de profesión y revolución. Cima.

Cajias de la Vega, M. (2004). El componente anarquista en el discurso minero del pre-52. Estudios Bolivianos, 12, pp. 15-78.

Committee on Armed Services of the U.S. Senate (1979). Stockpile Commodity Legislation Hearing, Washington. U.S. Government Printing Office.

Debray, R. (1975). Che's Guerrilla War. Penguin Books.

Dorn, G.J. (2011). Pushing Tin: U.S.-Bolivian Relations and the Coming of the National Revolution. Diplomatic History, 35 (2), pp. 202-228.

Ervin, C.W. (2006). Tomorrow is Ours: The Trotskyist Movement in India and Ceylon 1935-48. Social Scientists' Association.

Foreign Relations of the United States (1965). Diplomatic Papers 1943, vol. 5. Government Printing Office.

Goldenberg, B. (1971). Kommunismus in Lateinamerika. Kohlhammer.

Hernández, J.L. (2017). Bajo la bandera de la revolución permanente. Ideas de Izquierda, 38, junio, pp. 42-44.

John, S.S. (2016). El trotskismo boliviano: Revolución permanente en el Altiplano. Plural.

Klein, HS. (1969). Parties and Political Change in Bolivia, 1880-1952. Cambridge University Press.

Lora, G. (1963). La Revolución Boliviana. Difusión.

- (1972). Bolivia: De la Asamblea Popular al golpe fascista. El Yunque.

- (1978). Contribución a la historia politica de Bolivia, 2 tomos. Isla.

- (1995). Obras completas, t. IV (1950-1953). Ediciones Masas.

Malloy, J.M. y E. Gamarra (1988). Revolution and Reaction: Bolivia 19641985. Transaction Books.

Marof, T. [Gustavo Navarro] (1926). La justicia del Inca. La Edición Latino Americana.

Murillo, M. (2011). La bala no mata sino el destino: Una crónica de la insurrección popular de 1952 en Bolivia. Plural.

Nash, J.C. (2007). Practicing Ethnography in a Globalizing World. AltaMira Press.

Paz Estenssoro, V. (1954). El pensamiento revolucionario de Paz Estenssoro, Edición Fundamentos y Doctrina de la Secretaría Ejecutiva del Comité Politico Nacional del M.N.R.

Salazar Mostajo, C. (1989). La pintura contemporánea de Bolivia. Juventud. - (1997). ;Warisata mía! Juventud.

- (2003). Caducidad de una estrategia (2a ed.). Juventud.

Taboada Terán, N. (1960). El precio del estaño. Juventud.

Ticona Alejo, E. (2003). La Revolución Boliviana y los pueblos indígenas. En Tenemos pechos de bronce...pero no sabemos nada. Plural, pp. 284-296. Van, N. (1995). Revolutionaries they could not break: The fight for the Fourth International in Indochina 1930-1945. Index. 
Whitehead, L. (1991). Bolivia Since 1930. En L. Bethell (ed.). The Cambridge History of Latin America, VIII, Cambridge University Press, pp. 509-583. Zavaleta Mercado, R. (1959). El ampliado minero y la clandestinidad [1959]. En Hojas de mi archivo, junio de 1992, La Paz, pp. 3-13.

- (1974). El poder dual en América Latina. Siglo Veintiuno. 